\title{
CLINICAL AND RADIOGRAPHIC EVALUATION OF CHITOSAN-ZINC OXIDE EUGENOL MIX IN PULP CAPPING OF PRIMARY TEETH
}

\author{
Ahmed Ismail Basiony Alhamshary *, Samy Youssef El-Bayoumy ${ }^{* *}$, Abd-Elhamid Abu-Elyazed Eisa ${ }^{* * *}$
}

\begin{abstract}
Objective: The objective of this study was to evaluate clinically and radiographically the chitosan-zinc oxide eugenol mix as pulp capping material in primary teeth. Materials \& Methods: The study was performed on 36 primary molars of patients aged from 4-8 years that were indicated for pulpotomy. The teeth were divided randomly into 2 main equal groups. Each group formed of 18 primary molars. Group A: 18 children teeth in which zinc oxide and eugenol (ZO/E) was used as pulp capping material after formocresol (FC) application. Group B: 18 children teeth in which Chitosan-ZO/E mix was used as pulp capping material. The teeth were assessed clinically and radiographically at 4 different intervals (preoperative, 24 hours, 6 weeks and 3 months postoperative), using standard clinical and radiographic criteria. Results: It was found that chitosan-ZO/E mix offers good clinical and radiographic results when compared with $\mathrm{ZO} / \mathrm{E}$ after application of FC but with no statistically significant differences. Conclusion: ZO/E after application of FC (group A) showed (83.33\%) success rate, while the Chitosan-ZO/E mix (group B) showed a higher success rate $(94.44 \%)$. Chitosan-ZO/E mix is a promising material as pulp capping material with a high success rate and showing competitive properties to $\mathrm{ZO} / \mathrm{E}$ after $\mathrm{FC}$ application.
\end{abstract}

Key words: primary teeth, pulpotomy, ZO/E, FC, chitosan-ZO/E mix.

\section{INTRODUCTION}

Oral health is a major public health issue affecting all groups of the population. Poor oral health during childhood is directly accompanied with poor oral health outcomes in childhood and throughout adulthood, as people remain susceptible to developing dental caries throughout their lives ${ }^{(1)}$.

Dental caries is the most prevalent chronic disease, afflicting a significant proportion of the world population, including around $60 \%$ to $90 \%$ of school-aged children and the vast majority of adults. Dental caries occurs because of demineralization of tooth structure by organic acids formed by oral bacteria present in dental plaque through the anaerobic metabolism of dietary sugars ${ }^{(2)}$.
Healthy primary teeth maintain the space for their permanent successors developing in the jaw underneath. Their premature loss, from tooth decay or injury, often results in loss of space for their successors and may lead to crowding problems with the permanent dentition ${ }^{(3)}$.

Treatment of pulpaly involved teeth in primary and immature permanent teeth presents unique challenges. It is generally agreed that the dental pulp in the primary teeth, has a high potential for the repair. However, there are questions concerning the techniques and materials which offer the highest percentage of success ${ }^{(4)}$

Pulpotomy is one of the most used frequently treatment for retaining cariously pulp involved

\footnotetext{
* B.D.S (2008), Faculty of Dental Medicine, Boys, Assuit, Al-Azhar University.

** Professor, Department of Pedodontics and Oral Health, Faculty of Dental Medicine, Boys, Cairo, AL-Azhar University

**** Lecturer of Pedodontics and Oral Health, Faculty of Dental Medicine, Boys, Cairo, Al Azhar University.
} 
primary teeth. Pulpotomy is performed in a primary tooth with extensive caries but without evidence of radicular pathology when caries removal results in a carious or mechanical pulp exposure. It is a conservative therapy performed to remove the inflamed coronal pulp tissues followed by application of an effective and compatible bactericidal medicament ${ }^{(5)}$.

Different materials have been used for performing pulpotomies of primary teeth. Formocresol (FC) has been a popular material of choice for pulpotomy procedure in the primary teeth, because of its ease in use and excellent clinical success. Concerns have been expressed about FC pulpotomy because of inflammation and necrosis, cytotoxicity, systemic disturbance, mutagenic, carcinogenic potential and immunologic response ${ }^{(6)}$.

Zinc oxide-eugenol $(\mathrm{ZO} / \mathrm{E})$ is one of the materials that is used as pulp dressing after FC pulpotomy. It provides analgesic properties and a potent antibacterial action against Staphylococcus, Micrococci, Bacillus and Enterobacteria for more than 30 days. Furthermore, ZO/E provides an effective seal, thereby limiting microleakage and subsequent recurrent infection ${ }^{(7)}$.

However, diverse toxic effects have been reported when $\mathrm{ZO} / \mathrm{E}$ is applied directly over the pulp because of eugenol irritating effect, so the eugenol component of the paste has been associated with claims of failure in primary molar pulpotomy ${ }^{(8,9)}$.

Chitosan has emerged as a potential material for biodental applications corresponding to its unique properties such as bioactivity, antimicrobial, biocompatibility and compatibility to blend with other materials. The chitosan-based materials have been explored extensively for a wide range of dental applications ${ }^{(10)}$.

The chemical modifications of chitosan through its functional groups have extended its range of applications, improving its mechanical properties, its solubility, among others. Chitosan is a promising material because in addition to various applications, it is a product that is produced from waste seafood ${ }^{(11)}$. Therefore the aim of the this study was to evaluate the beneficial effect of adding Chitosan to traditional $\mathrm{ZO} / \mathrm{E}$ as a pulp capping material.

\section{MATERIALS AND METHODS}

Thirty six badly decayed vital primary molars indicated for pulpotomy in patients selected from Pedodontic outpatients clinic, Faculty of Dental Medicine, Boys, Cairo, Al-Azhar University, were selected. The age of the patients ranged from $4-8$ years old.

\section{Sample size}

A sample size of 18 in each group that has a $80 \%$ power was selected to detect a difference between means of 4.60 with a significance level (alpha) of 0.05 (two-tailed).

Pulpotomy was performed in 36 badly decayed primary molars that divided into two equal groups according to material used in pulpotomy:

Group A: 18 primary molars received ZO/E as pulp capping material after $\mathrm{FC}$ application.

Group B: 18 primary molars received Chitosan$\mathrm{ZO} / \mathrm{E}$ mix as pulp capping material.

\section{Eligibility criteria of population}

\section{Inclusion criteria:}

1. Children age (from 4 to 8 years old).

2. Vital primary molars.

3. Acute pulpitis not extending periapically.

4. Not treated with antibiotic at least two weeks befor treatment.

5. Possibility for establishing a final restoration of the tooth.

6. Patient and parent cooperation. 


\section{Exclusion criteria:}

1. Non vital primary molars.

2. History of spontaneous, unprovoked toothache.

3. Mobility, (grade I, II and III).

4. Sensitivity for percussion.

5. The child receives chemotherapy or radiotherapy.

6. Systemic diseases.

\section{Preparation of Chitosan-ZO/E mix}

Chitosan polymer powder $(70 \%$ deacetylated, Oxford Lab Chem, Mumbai, India) was mixed with zinc oxide powder (PREVEST DenPro,India). Chitosan powder was $20 \%$ and zinc oxide powder $80 \%$ by weight. The mixed powder was then mixed with an appropriate amount of eugenol (DHARMA, USA) when applied into pulpotomized primary molars.

\section{Intervention}

Initially, the cavity outline was prepared with large round bur rotating at ultrahigh speed. All the carious dentin was removed before penetrating the pulp chamber and all the undermined enamel was removed. An access opening was then established into the pulp chamber and the entire roof was removed. At all times, the designated tooth was cooled by a steady stream of water and air. Amputation of the coronal pulp at pulp chamber till the orifices of the canals was performed using sharp large spoon excavator with lateral thrusts. A thick layer of the applied material was placed over the pulp orifices after homeostasis. Glass ionomer filling was the final restoration Figure (1).

\section{Ethical consideration}

The study was approved by the pedodontics scientific Committee and department council, Faculty of Dental Medicine, Boys, Cairo, Al-Azhar University. A signed informed consent was done from the parents of each child prior to beginning the study.

\section{Statistical Analysis:}

Data was statistically analyzed using SPSS statistical program (Statistical Package for Social Sciences) version 21 for windows. A value of $\mathrm{P} \leq$ 0.05 was considered statistically significant. Chi square test and odd ratio were performed for data analysis.

\section{RESULTS}

Clinical and radiographic examinations were done preoperative at, 24hours, 6 weeks and three months post-treatment. Patients' assessments were done on every visit and the success rate was regularly calculated. But the final outcome was taken after evaluating results on the last visit.

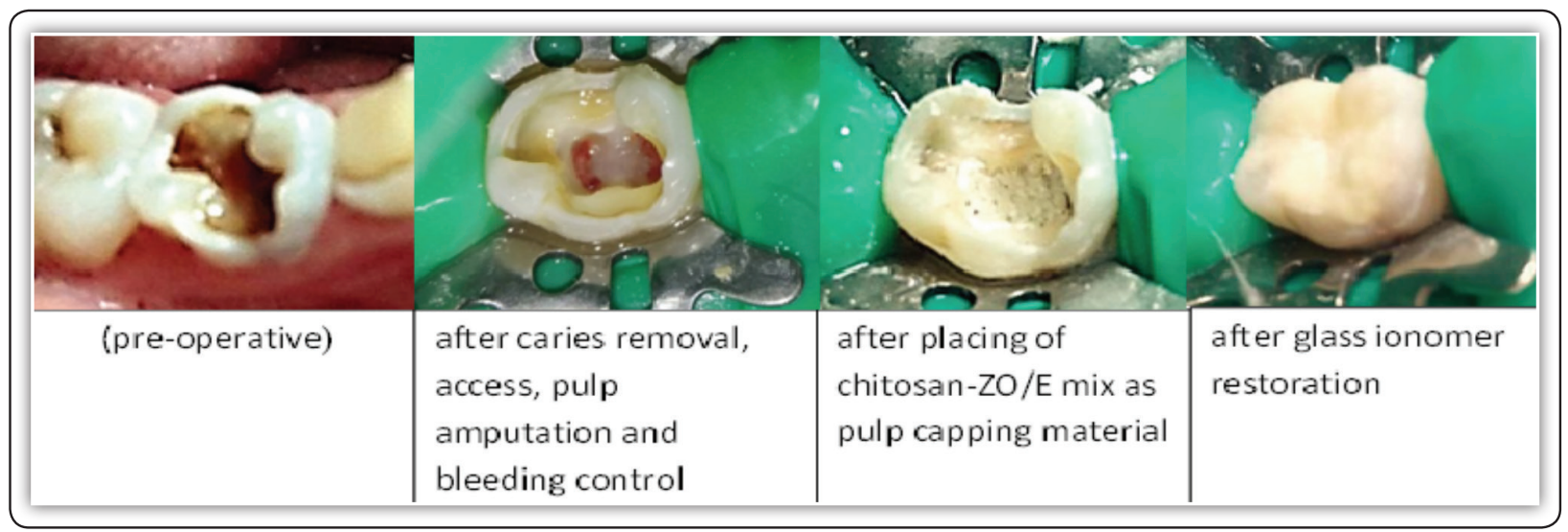

FIG (1) Badly decayed lower right second primary molar was pulpotomized and treated with chitosan-ZO/E mix as pulp capping material. 
Presence of acute pain, tooth mobility, apical periodontitis (acute or chronic), radiographic evidence of pulp degenerative changes or loss of vitality was regarded as an indicator of a failed treatment.

\section{Clinical and radiographic evaluation:}

The cases treated were considered successful clinically if there was absence of pain, tenderness on percussion pathology, absence of swelling or fistula and absence of mobility. The cases were considered successful radiographically, when demonstrated no signs of the radiolucency. Appearance of radiolucency was considered as a radiographic failure.

All cases were examined for clinical and radiographic symptoms prior to the procedure that was recorded. Pre-operative and follow-up clinical factors are summarized in the table (1).

After 3 months follow up in Chitosan-ZO/E group, only 1 tooth complained of pain, 1 tooth complained of tenderness to percussion and none of the teeth complained of mobility and gingival swelling or sinus tract. Meanwhile in $\mathrm{ZO} / \mathrm{E}$ group, three teeth complained of pain, 3 teeth complained of tenderness to percussion and 1 tooth complained of mobility and gingival swelling or sinus tract. Clinically, postoperative evaluation revealed that there was reduction in clinical signs and symptoms, which was statistically highly significant but the difference between the two groups $(P=0.5921>$ $0.5)$ was non-significant statistically.

The success of the treatment was determined after follow up period of 3 months. In Chitosan$\mathrm{ZO} / \mathrm{E}$ the success rate clinically and radiographically was $94.44 \%$, i.e., 17 out of 18 teeth while in $\mathrm{ZO} / \mathrm{E}$ group it was $83.33 \%$, i.e., 15 out of 18 teeth, were considered successful as these teeth were asymptomatic and clinical as well as radiographical signs of pathology were absent.

Odd ratio (OR) was calculated using approximation of Woolf (Odd ratio $=0.7741$ at $95 \%$ confidence intervals $(0.3834-1.563)$. If the $\mathrm{OR}$ is $>1$ the control is better than the intervention. If the OR is $<1$ the intervention is better than the control. So group $\mathrm{B}$ better than group $\mathrm{A}$ because Odd ratio = $0.7741<1$

TABLE (1) Comparative clinical evaluation between both groups, preoperatively, 24hours, 6weeks and 3months postoperatively

\begin{tabular}{|c|c|c|c|c|c|}
\hline & & \multicolumn{4}{|c|}{ Material group } \\
\hline \multirow{2}{*}{\multicolumn{2}{|c|}{ Variables }} & \multicolumn{2}{|c|}{ Chitosan-ZO/E } & \multicolumn{2}{|c|}{$\mathrm{ZO} / \mathrm{E}$} \\
\hline & & Yes & No & Yes & No \\
\hline \multirow{4}{*}{ Follow up time } & Pre-operative & $10(55.56 \%)$ & $8(44.44 \%)$ & $11(61.11 \%)$ & $7(38.89 \%)$ \\
\hline & After 24hours & $10(55.56 \%)$ & $8(44.44 \%)$ & $11(61.11 \%)$ & $7(38.89 \%)$ \\
\hline & After 6weeks & $1(5.56 \%)$ & 17 (94.44\%) & $2(11.11 \%)$ & $16(88.89 \%)$ \\
\hline & After 3months & $0(0 \%)$ & $18(100 \%)$ & $1(5.56 \%)$ & $17(94.44 \%)$ \\
\hline \multirow{2}{*}{ Chi square Test } & \multirow{2}{*}{$P$ value } & \multicolumn{2}{|c|}{$<0.0001^{*}$} & \multicolumn{2}{|c|}{$<0.0001^{*}$} \\
\hline & & \multicolumn{4}{|c|}{$0.5921 \mathrm{~ns}$} \\
\hline
\end{tabular}

*: significant $(p<0.05)$

ns: non-significant $(p>0.05)$

The below figures are perapical radiographs of a case of chitosan-ZO/E mix pulp capping for pulpotomized lower right first primary molar of boy 6 years old was seen in figure (2). 


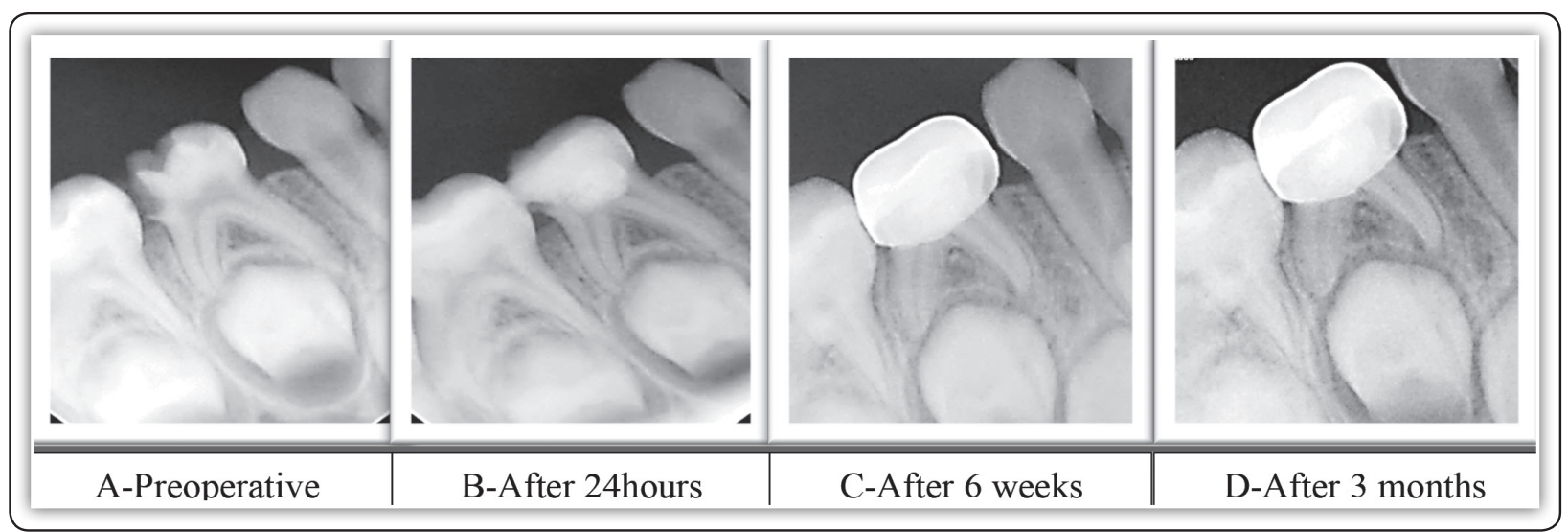

FIG (2) Chitosan-ZO/E mix pulpotomy for primary molar of boy 6 years old (group B).

\section{DISCUSSION}

In the present study in group A, the success rate was approximately (83.33\%) showed no signs and symptoms of inflammation which appear clinically and radiographically. Studies done by Holan et al. ${ }^{(12)}$, Fuks et al. ${ }^{(13)}$, and Olatosi et al. ${ }^{(14)}$, showed that success rate of FC pulpotomy was $(83 \%, 84 \%$ and $81 \%$ ) respectively and showed a good agreement with our study.

Better effectiveness of FC pulpotomy is emphasized by Mostafa et al. ${ }^{(15)}$ and El- Meligy et al. ${ }^{(16)}$, which reported (94.7\% and 100\%) clinical success rate, while radiographically reported $(84.1 \%$ and $87.5 \%$ ) success rate respectively.

On the other hand, other studies have a lower success rates of FC pulpotomy than our study such as Farooq et al. which reported a $74 \%$ success rate ${ }^{(17)}$. Also Holan et al. scored $77 \%$ success ${ }^{(18)}$.

The clinical and radiographic success rate of FC is credited to the antimicrobial action and fixative properties of FC which is due to chemical bonding with the proteins of microorganisms ${ }^{(19)}$.

The clinical and radiographic failure rates observed in group Awas in theform ofpain, tenderness to percussion, mobility and gingival swelling or sinus tract. Additionally, radiographic examination revealed widening in periodontal ligament space, periapical and furcation radiolucencies with varying degrees. An explanation of that failure could be due to the presence of chronic inflammation in the residual pulp at the time of treatment and as such leading to diagnostic errors or it may be due to anachoresis (The transportation of foreign bodies via blood or lymph nodes and subsequent collection at the site of inflammation) ${ }^{(20)}$.

$\mathrm{ZO} / \mathrm{E}$-based restorative material is one of the most commonly used restorative materials in dentistry and it is widely used as a base in pulpotomies because of its antibacterial and analgesic properties. The antibacterial and bacteriostatic effects of ZO/Ebased materials are partly mediated by leaching of eugenol. The free hydroxyl groups in eugenol are thought to cause damage to the cell membrane by altering the permeability of the membrane followed by leakage of the cellular content. Furthermore, $\mathrm{ZO} / \mathrm{E}$ provides an effective seal, thereby limiting microleakage and subsequent recurrent infection ${ }^{21}$, 22).

The antibacterial activity of ZO/E-based materials reduces over time ${ }^{(23)}$. Increasing the eugenol content may not be recommended due to its cytotoxic effect on human osteoblastic cells (24). Although $\mathrm{ZO} / \mathrm{E}$ is an obtundant, it does not apparently suppress metabolism adequately or 
self-limit its irritative properties, so it is cytotoxic to the pulp cells when $\mathrm{ZO} / \mathrm{E}$ come in direct contact with the pulp. Chronic inflammation persists for extended periods of time after application of $\mathrm{ZO} / \mathrm{E}$ causing internal resorption ${ }^{(22,25)}$.

In group B (Chitosan-ZO/E pulpotomy) showed that success rate was approximately $(94.44 \%)$ since 17 teeth from 18 showed no signs and symptoms of inflammation which reported clinically and radiographically.

The promising clinical outcome of vital pulpotomy performed with Chitosan-ZO/E mix may be explained on the bases that were found to chitosan that possess antimicrobial properties, biocompatibility, and has no toxic effect in addition to increasing the antimicrobial and anti-biofilm properties of $\mathrm{ZO} / \mathrm{E}^{(26)}$.

The most important property of chitosan derivatives is the antimicrobial activity exerted against bacteria, viruses, fungi, and even algae. It has been shown to have antibacterial effect on $S$. mutans, Aggregatibacter actinomycetemcomitans, and Porphyromonas gingivalis in vitro ${ }^{(27)}$. The antibacterial activity of chitosan could originate from bacteria cell and DNA binding mechanisms by its positively charged amino group ${ }^{(28)}$.

Chitosan has started to be used as a hemostatic agent in the treatment of pulpotomized primary teeth which diluted with sterile saline and applied to the pulp chamber. Also Chitosan increases the formation of reparative dentin and the formation of hard tissue which reported to be an appropriate material for pulpotomy ${ }^{(29,30)}$.

The study by DaSilva et al. evaluated roots of bovine teeth filled with gutta-percha and sealer $(15 \%$ chitosan nanoparticles incorporated with $\mathrm{ZO} / \mathrm{E}$ ). It is suggested that chitosan nanoparticles may leach out of the sealer mass providing diffusible antibacterial properties while at the same time inhibiting the surface adherence of E. faecalis ${ }^{(31)}$.
Histopathological effects were evaluated in rat experiments with the application of chitosan monomer as a pulp capping medicament. It is concluded that ideal tissue regeneration in pulp wounds and a minimal initial inflammation reactions occurred ${ }^{(32)}$.

In the present study the clinical and radiographic failure rate obtained with group B was 5.56\% (one case of 18 pulpotomized primary molars), after the follow-up periods at 3 months. The failure was in the form of pain, tenderness to percussion and none of the teeth complained of mobility and gingival swelling or sinus tract. Additionally, radiographic examination revealed widening in periodontal membrane space and internal resorption. The failures can be attributed to undiagnosed inflammation in the residual pulp before the treatment or contamination occurs due to a microleakage of restorative material ${ }^{(33)}$.

The investigation revealed good results at the end of the follow up period ( 3 months) with both chitosan-ZO/E mix and FC treated teeth with no statistically significant differences.

More researches are recommended with more participants and longer follow-up periods and more investigation of systemic and histological effects of Chitosan-ZO/E mix on pulp tissues.

\section{CONCLUSION}

From the results of the present study, the following conclusions can be drawn:

- Chitosan-ZO/E mix is a promising material as pulp capping material with a high success rate and showing competitive properties to $\mathrm{ZO} / \mathrm{E}$ after FC application.

- Chitosan-ZO/E mix offers good clinical and radiographical results when compared with $\mathrm{ZO} / \mathrm{E}$ after $\mathrm{FC}$ application but with no statistically significant differences.

- Chitosan-ZO/E has the power to be an alternative for $\mathrm{ZO} / \mathrm{E}$ after $\mathrm{FC}$ application in pulpotomized primary molars 


\section{REFERENCES}

1. Dallas S, Li J, Kruse K and McBride-Henry K. A Literature Review on Oral Health in Preschoolers. Health Promotion Agency. 2015.

2. Marinho VC, Chong LY, Worthington HV and Walsh T. Fluoride mouthrinses for preventing dental caries in children and adolescents. Cochrane Database Syst. Rev. 2016.

3. Benzian $\mathrm{H}$ and Williams D. The challenge of oral disease: a call for global action. The oral health atlas 2nd ed Geneva: FDI World Dental Federation. 2015.

4. Hugar SM, Reddy R, Deshpande SD and Hugar SS. In vivo comparative evaluation of mineral trioxide aggregate and formocresol pulpotomy in primary molars: A 60-month follow-up study. Contemporary clinical dentistry. 2017; 8: 122-7.

5. Goyal P, Pandit I, Gugnani N and Singla V. Clinical efficacy of various medicaments used for pulpotomy in primary molars-A comparative study. IJRDPL. 2016; 5: 2107-16.

6. Bagrizan M, Pourgolshani P, Hosseinpour S and Shahrestani MZ. Plasma Level Formaldehyde in Children Receiving Pulpotomy Treatment under General Anesthesia. Int. J. Clin. Pediatr. Dent. 2017; 41: 95-101.

7. Luengo J, Reyes H, Toscano I and Anaya M. Clinical and Radiographic Evaluation of CTZ (Chloramphenicol-Tetracycline-Zinc Eugenol Oxide) Antibiotic Paste in Pulp Treatment of Primary Molars. J Dent Health Oral Disord Ther. 2017; 8: 00272.

8. Escobar-García M, Rodríguez-Contreras K, Ruiz-Rodríguez S and Pozos-Guillén A. Eugenol toxicity in human dental pulp fibroblasts of primary teeth. Int. J. Clin. Pediatr. Dent. 2016; 40: 312-8.

9. Atasever G, Keceli T, Uysal S and Olmez S. Primary molar pulpotomies with different hemorrhage control agents and base materials: A randomized clinical trial. Niger. J. Clin. Pract. 2019; 22: 305-12.

10. Husain S, Al-Samadani KH, Najeeb S, et al. Chitosan biomaterials for current and potential dental applications. Materials. 2017; 10: 602-22.

11. Hosseinnejad M and Jafari SM. Evaluation of different factors affecting antimicrobial properties of chitosan. Int. J. Biol. Macromol. 2016; 85: 467-75.

12. Holan G, Eidelman E and Fuks AB. Long-term evaluation of pulpotomy in primary molars using mineral trioxide aggregate or formocresol. Pediatr Dent. 2005; 27: 129-36.

13. Fuks A, Holan G, Davis J and Eidelman E. Ferric sulfate versus dilute formocresol in pulpotomized primary molars: long-term follow up. Pediatr Dent. 1997; 19: 327-30.
14. Olatosi OO, Sote EO and Orenuga OO. Effect of mineral trioxide aggregate and formocresol pulpotomy on vital primary teeth: a clinical and radiographic study. Niger. J. Clin. Pract. 2015; 18: 292-6.

15. Mostafa AA, El Hosary AM and Zahra MK. Clinical and radiographic evaluation of platelet-rich fibrin as a pulpotomy agent in primary molars. Tanta Dent. J. 2018; 15 : 70-75.

16. El Meligy OAES, Alamoudi NM, Allazzam SM and ElHousseiny AAM. Biodentine TM versus formocresol pulpotomy technique in primary molars: a 12-month randomized controlled clinical trial. BMC oral health. 2019; 19: 1-8.

17. Farooq NS, Coll JA, Kuwabara A and Shelton P. Success rates of formocresol pulpotomy and indirect pulp therapy in the treatment of deep dentinal caries in primary teeth. Pediatr Dent. 2000; 22: 278-86.

18. Holan G, Fuks A and Ketlz N. Success rate of formocresol pulpotomy in primary molars restored with SSC vs amalgam. Pediatr dent. 2001; 24: 212-6.

19. Hugar SM and Deshpande SD. Comparative investigation of clinical/radiographical signs of mineral trioxide aggregate and formocresol on pulpotomized primary molars. Contemporary clinical dentistry. 2010; 1: 146-51.

20. Narayanan LL and Vaishnavi C. Endodontic microbiology. J Conserv Dent. 2010; 13: 233-9.

21. Marchese A, Barbieri R, Coppo E, et al. Antimicrobial activity of eugenol and essential oils containing eugenol: A mechanistic viewpoint. Critical reviews in microbiology. 2017; 43: 668-89.

22. Pratima B, Chandan G, Nidhi T, et al. Postoperative assessment of diode laser zinc oxide eugenol and mineral trioxide aggregate pulpotomy procedures in children: A comparative clinical study. J Indian Soc Pedod Prev Dent. 2018; 36: 308-14.

23. Slutzky H, Slutzky-Goldberg I, Weiss E and Matalon S. Antibacterial properties of temporary filling materials. J. Endod. 2006; 32: 214-7.

24. Ho YC, Huang FM and Chang YC. Mechanisms of cytotoxicity of eugenol in human osteoblastic cells in vitro. Int Endod J. 2006; 39: 389-93.

25. Escobar-García M, Rodríguez-Contreras K, Ruiz-Rodríguez M and Pozos-Guillen A. Eugenol Toxicity in Human Dental Pulp Fibroblasts of Primary Teeth Eugenol Toxicity in Human Dental Pulp Fibroblasts of Primary Teeth. Int. J. Clin. Pediatr. Dent. 2016; 40: 312-8. 
26. Dragland IS, Wellendorf $\mathrm{H}$, Kopperud $\mathrm{H}$ and Valen $\mathrm{H}$. Investigation on the antimicrobial activity of chitosanmodified zinc oxide-eugenol cement. Biomaterial investigations in dentistry. 2019; 6: 99-106.

27. Erpaçal B, Adıgüzel Ö, Cangül S and Acartürk M. A General Overview of Chitosan and its Use in Dentistry. International Biological and Biomedical Journal. 2019; 5: 1-11.

28. Chen C-Y and Chung Y-C. Antibacterial effect of watersoluble chitosan on representative dental pathogens Streptococcus mutans and Lactobacilli brevis. J Appl Oral Sci. 2012; 20: 620-7.

29. Rinaudo M. Chitin and chitosan: properties and applications. Progress in polymer science. 2006; 31: 603-32.
30. Delikan E. Hemostatic agents for pulpotomy treatment in primary teeth. Yeditepe J Dent. 2018; 14: 109-16.

31. DaSilva L, Finer Y, Friedman S and Kishen A. Biofilm formation within the interface of bovine root dentin treated with conjugated chitosan and sealer containing chitosan nanoparticles. J. Endod. 2013; 39: 249-53.

32. Matsunaga T, Yanagiguchi K, Yamada S and Hayashi Y. Chitosan monomer promotes tissue regeneration on dental pulp wounds. J. Biomed. Mater. Res. 2006; 76: 711-20.

33. Kathal S, Gupta S, Bhayya DP and Sabhlok A. A comparative evaluation of clinical and radiographic success rate of pulpotomy in primary molars using antioxidant mix and mineral trioxide aggregate: An in vivo 1-year follow-up study. J Indian Soc Pedod Prev Dent. 2017; 35: 327-31. 